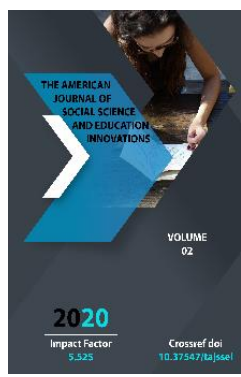

\title{
Peculiarities Of Developing Critical Thinking In Primary School Students In The Process Of English Language Teaching
}

Mamadjanova Nozima Adhamovna

PhD Student Of Namangan State University, Uzbekistan

Copyright: Original content from this work may be used under the terms of the creative commons attributes 4.0 licence.

\section{ABSTRACT}

This article discusses that the ability to think critically does not develop spontaneously. On the contrary, teachers play a major role in the development and management of the learning process. Foreign language classes help to develop critical thinking through a variety of materials and interactive learning technologies. Exploring the essence of critical thinking allowed him to move on to taking into account his abilities. As a result of studying this problem, it can be said that the foreign literature pays special attention to critical thinking skills.

\section{KEYWORDS}

Curiosity, sensitivity, self-confidence, independence, openness, freedom of thought (freedom), courage, activism and goalsetting.

\section{INTRODUCTION}

Teaching students critical thinking in the English language teaching process remains one of the main goals of the learning process in the continuing education system. The development of critical thinking is a process of education and upbringing, as a result of which the natural human qualities such as curiosity, sensitivity, self-confidence, independence, openness, freedom of thought (freedom), courage in expressing ideas are actualized and developed. The ability to form critical thinking and teach students determines the level of professionalism of the teacher, which directs students to critical thinking. The effectiveness of student activities and, accordingly, the effectiveness of the learning process depends 
on the students' critical thinking, perception, memorization, comprehension and other thinking processes. As this type of thinking is social and the most fully manifested in public speech, discussion, conflict when the teacher interacts with students and pupils.

Students and teachers are always trying to learn from their own and others'experiences. Such a situation always requires monitoring the development of their ideas, analyzing their activities, relying on the scientific recommendations of pedagogical science, comparing work experience with the experience of other people, critically evaluating their successes and shortcomings. All work in foreign language teaching is based on the creative collaboration of teacher and student, the development of students' analytical approach to any material, through cognitive activity emerges a chain of studentteacher, teacher-student, student-student interaction.[1]

The development of students' critical thinking is the result of the interaction of teacher and students, and the degree of its formation, in turn, depends on the correct choice of forms of organization of learning. Some researchers point out in their work that the use of the traditional form does not fully develop the individual because it does not allow the development of the qualities needed to work in a team.

The practical application of the principle of humanity in the learning process requires pedagogical technologies based on the ability to take an active approach to the individual, critical, creative thinking, problem-solving, decision-making and teamwork.[5]

\section{MATERIALS AND METHODS}

The foundations for developing critical thinking in students are two interrelated aspects. On the one hand, the development of critical thinking through a foreign language increases the effectiveness of the learning process, on the other hand, each of the primary school students forms a culture of critical thinking.

Personal characteristics allow students to actively trust them in the practice of forming critical thinking: activism, active principle, goal setting, reflection, responsibility. Let's take a closer look at them.

Activism. Initially active, a person becomes a subject in the process of individual communication, activity, and other activities. It should be noted that the implementation of the theme is carried out only "when there is an appropriate social environment."

The active principle of each subject. The theme of the activity is characterized by the ability to produce, change objects and ideas, create new ones; focus on realizing "self ..."; stability of views, beliefs, meanings, reasons; having individual characteristics that stimulate the desire for mutual cooperation, collaboration, communication. The center of activity is the object-object relationship. K.A. AbulkhanovaSlavskaya argues that activity is not an independent entity, its essence stems from the essence of form. When the topic category takes the lead in the analysis, an important relationship between the subject and the activity is identified. The unity of objective and subjective in activity is characterized by such important features of activity as goal setting, objectivity, meaningfulness, transformational character.[5] 
Our study focuses on educational activities that reveal "internal and necessary relationships in the material. Creates: contributes to the question-answer activities of students, stimulates them to their own experiences, creates the conditions for its structural correction and correction, organizes joint activities to understand the content of education.

We agree with the view that internal motivation provides higher productivity and critical thinking efficiency than external. In this regard, we were interested in the factors that help to shape the internal motivation of students to think critically. F. According to Gertsberg, many researchers who study motivation have misinterpreted that a person is isolated from a particular learning environment, however, any activity takes place at a specific time and place.[6]

We examined the teacher's attitude that encourages critical thinking: 1) changes in learning are common to all, all of our students want it; 2) students are ready to take responsibility for their own learning outcomes; 3) external rather than external factors prevent the expression of imagination, creativity and intelligence in learning (such limiting factors include the education system itself, existing educational models or stereotypes). work in society); 4) All students are capable of significant self-development

The analysis of the scientific literature identified the following groups of motives influencing the development of students' critical thinking:

1) Cognitive motives related to the content of educational activities and the process of its implementation;
2) Social reasons related to the student's different social relationships with other people.

Goal setting. Topics of critical thinking are characterized by "the ability to deviate from the tasks and requirements of direct reality" That is, it sets new goals. The purpose of the activity is the expected result. The goal can be general or specific, distant or near, external or internal, conscious or absent. Goal setting means predicting and predicting the expected outcome. A well-understood and defined goal leads to a corresponding outcome of the person who shapes it. Goals are developed by people, that is. they are subjective. But the source of their origin is objective, that is. humanity sets tasks that it can solve on its own. Goals are objective-subjective in nature.

As the subject of the formation of student critical thinking, we have identified the following groups of objectives:

- Personal goals - understanding of educational goals; self-confidence, selfefficacy; realization of creative abilities. They are characterized by: recognition of their position in individual and collective creativity; in mastering personal thinking and self-management skills; at the level of self-determination, achieved as a result of conscious self-awareness and selfexpression;

- Objective goals - to form a positive attitude to the subject; knowledge of basic concepts, events, and laws that are part of the subject being studied; solve custom or creative tasks on a topic;

- Creative goals - creating a set of tasks; creation of a natural path; technical model design; drawing; 
- Cognitive goals - to know the objects of reality around; learning how to solve problems; mastering the skills of working with primary resources; experimentation, experimentation;

- Organizational goals - mastering the skills of independent organization of creative activity; ability to set goals, plan activities; developing teamwork skills in a group; mastering heuristic techniques.

The goal for the topic of critical thinking is the result of independent action. The conditions for the formation of new goals may be: the emergence of new needs and motives, the acquisition of new knowledge about possible outcomes, the adoption of new requirements, the emergence of difficulties, the emergence of new unconscious foresight.

To further develop students 'critical thinking, we explored the characteristics of the student period. This is defined by young psychologists as late adolescence or early puberty. At the student age, not only physical but also psychological features and higher mental functions are maximized: cognition, attention, memory, thinking, speech, feelings and emotions. It is during this period that an understanding of a person's place in life emerges. From a socio-psychological point of view, students are different from other groups of the population.

High level of education, active consumption of culture and high level of cognitive motivation. Students are a social association characterized by the highest social activity. Youth is characterized by the rapid development of hypothetical-deductive thinking, the ability to form and select alternative hypotheses to solve cultural situations, to formulate problems independently, and to turn their thoughts into the subject of analysis. The central psychological process is the formation of a person's worldview and identity, which is manifested by a desire for self-expression, a desire to express the person. Researchers highlight the ability to reflect and set goals as one of the neoplasms of youth. The first and second courses of linguistics faculties form the basis of knowledge of a foreign language. This stage is very important for the formation of skills and daily communication skills, as evidenced by the topics covered in many textbooks and textbooks for 1st and 2nd year students of the faculties. Teachers place great emphasis on mastering and teaching relevant grammatical and lexical materials organized on a thematic principle based on language, conditioned speech and speech exercises, situations and role-plays.

Thus, the student period is a favorable period for the student's independent critical thinking. Therefore, a student is a person who is active in learning activities, knows how to set goals, interacts with teachers and other students, changes ways and means of action depending on the situation, forms problems, makes decisions. The student has personal qualities, actively masters the methods and mechanisms of its formation, is able to create a creative product independently ready for purposeful change and self-improvement in an active and constantly changing environment.

The role of the student in teaching foreign languages is his active participation in the learning process. The cognitive approach in foreign language teaching has been replaced by behavior. The learning process and the process of processing a student's data is more important than the actions of a foreign language teacher. 
Critical thinking should be taken into account in the process of teaching a foreign language, as life becomes more difficult to understand and the process of data processing becomes more important than real data. According to American scientists, S. Van Duser and M.S. Floreza, these foreign language teachers, contribute to a deeper understanding of meaning, not just simple! study the rules of grammar.[7]

\section{RESULTS AND DISCUSSIONS}

The ability to think critically does not develop spontaneously. On the contrary, teachers play a major role in the development and management of the learning process. Foreign language classes help to develop critical thinking through a variety of materials and interactive learning technologies. Exploring the essence of critical thinking allowed him to move on to taking into account his abilities. As a result of studying this problem, it can be said that the foreign literature pays special attention to critical thinking skills. This fact is explained by the fact that foreign education has a certain pragmatic character. The problem of interdependence of skills is much more complex and does not have the same explanation.

This document describes methods of teaching students individual thinking skills, the organization of the process of teaching a foreign language.

The analysis of the scientific literature identified the following groups of motives that affect the development of students' critical thinking:

1) Cognitive motives related to the content of educational activities and the process of its implementation;
2) Social reasons related to the student's different social relationships with other people.

Goal setting. Topics of critical thinking are characterized by "the ability to deviate from the tasks and requirements of direct reality," setting new goals. The purpose of the activity is the expected result. The goal can be general or specific, distant or near, external or internal, conscious or absent. Goal setting means predicting and predicting the expected outcome. A well-understood and defined goal leads to a corresponding outcome of the person who shapes it. Goals are developed by people, that is. they are subjective. But the source of their origin is objective, that is. humanity sets tasks that it can solve on its own. Goals are objective-subjective in nature.

As a subject for the formation of critical thinking in students, we identified the following groups of objectives:

- Personal goals - understanding of educational goals; self-confidence, selfefficacy; realization of creative abilities. They are characterized by: recognition of their position in individual and collective creativity; in mastering personal thinking and self-management skills; at the level of self-determination, achieved as a result of conscious self-awareness and selfexpression;

- Objective goals - to form a positive attitude to the subject; knowledge of basic concepts, events, and laws that are part of the subject being studied; solve custom or creative tasks on a topic;

- Creative goals - creating a set of tasks; creation of a natural path; technical model design; drawing; 
- Cognitive goals - to know the objects of reality around; learning how to solve problems; mastering the skills of working with primary resources; experimentation, experimentation;

- Organizational goals - mastering the skills of independent organization of creative activity; ability to set goals, plan activities; developing teamwork skills in a group; mastering heuristic techniques.

The goal for the topic of critical thinking is the result of independent action. Conditions for the formation of new goals can be: the emergence of new needs and reasons, the acquisition of new knowledge about possible outcomes, the adoption of new requirements, the emergence of difficulties, the emergence of new unconscious foresight

The study identified the following situations that encourage students to think critically:

1) Changes in learning should be normal for everyone, all students should want it;

2) Students must be prepared to take responsibility for their own learning outcomes;

3) Internal rather than external factors prevent the manifestation of imagination, creativity and intelligence (such limiting factors include the education system itself, existing models or stereotypes of educational work in society);

4) All students should be able to develop significantly on their own.

As a result of the use of critical thinking technology in primary school English lessons, the basis for creating a favorable environment for the organization of students' learning activities - communicative competence is formed.
The level of development of the student's speech ensures his mental development and social activity. In this regard, special attention should be paid to ensuring that primary school students learn English as well as their mother tongue perfectly within the requirements of the curriculum.

The practical orientation of school English lessons on the basis of interdisciplinary communication imposes certain requirements on the applied didactic material. Working on the link text in this regard is a good opportunity. We refer here to the link text as thematic texts (My family, Our school) that students create in collaboration with the teacher. Introducing language elements is not limited to working on a word, phrase, or individual sentence. It is well known that in the process of communication, sentences are used not as spontaneous but as elements of text. Therefore, the structure of the text cannot solve the problems of learning English without paying attention to the connections between its components.

In the process of using related text, students develop the ability to understand and create text created by others. Students develop their creative abilities through text-based exercises. Elementary students, on the other hand, develop communicative skills and competencies because text is the basic communicative unit of speech.

The following types of exercises can be used in the organization and implementation of work with text:

1) The return of the acquired knowledge according to the nature of the activity performed by the students, and the element of productive-creative research. 
2) According to the learning objectives defining (identification of language phenomena on the basis of their features), constructive (creation of language units of different structures) and creative;

3) By the nature of the original text: changes made or not made.

4) Speech exercises and communicative related to the analysis of language means according to the nature of speech texts.

\section{CONCLUSION}

The use of innovative teaching methods is an important tool to ensure the effectiveness of teaching in primary school English classes and to develop critical thinking skills in students. In particular, methods such as "mental attack", "cluster" can be widely used.

\section{REFERENCES}

1. Piaget, J. Psychology of intelligence [Text] / J. Piaget // Selected psychological works / J. Piaget. - M., 1969 .-- S. 55-229.

2. Clarin, M. V. Innovation in world pedagogy [Text]: learning based on research, games and discussions. (Analysis of foreign experience) / M.V. Klarin. - Riga: SPC "Experiment", 1995. - $176 \mathrm{p}$.

3. www.insightassessment.com. American Philosophical Association. Critical Thinking [Electronic resource]: A statement of expert consensus for purposes of educational assessment and instruction. The Delphi Report Executive Summary: Research findings and recommendations prepared for commitee on the pre-college philosophy / P. A. Facione. - Millbrae, CA: California Academic Press. - Access mode:

4. Paul, R. W. Critical Thinking. Fundamental to Education in a Free Society [Text]/ R. W. Paul // Educational Leadership. - 1984. - Vol. 42. - P. 4-14.
5. Halpern, D. Psychology of critical thinking [Text] / D. Halpern. - SPb. : Peter, 2000 .-$512 \mathrm{~s}$.

6. К.А. Abdulkxanova- "Деятельность и психология личности “

6.F. Gertsberg "Teoriyamotivatsii F. Gertsberga"

7. S. Van. Dyuzerand .M.S.Floreza 's ideas

8. Khodjaev B.I. Technology of cooperative education: opportunities and advantages // Innovation, integration and pedagogical technologies in education / Materials of the Republican scientific-practical conference. Namangan.-2019

9. Adhamovna, M. N. (2019). OPPORTUNITIES FOR DEVELOPING CRITICAL THINKING SKILLS IN EARLY CLASS STUDENTS. European Journal of Research and Reflection in Educational Sciences Vol, 7(12).

10. Mamadjanova, N. A. (2019). FACTORS FOR THE DEVELOPMENT OF CRITICAL THINKING SKILLS IN THE EDUCATIONAL PROCESS. Scientific Bulletin of Namangan State University, 1(4), 252-254.

11. Komilova, R. (2020). ТАНқИДИЙ ФИКРЛАШНИНГ АФЗАЛЛИКЛАРИ. АрхИв Научных Публикаций JSPI.

12. Sarimsakova, D. (2017). Station Rotation. English Teaching Professional, 109.

13. Sarimsakova, D. M. (2020). SOCIOLINGUISTIC COMPETENCE AND COMMON REFERENCE LEVELS OF THE CEFR. In МИРОВАЯ ЭКОНОМИКА. ПРОБЛЕМЫ, ПЕРСПЕКТИВЫ, ИННОВАЦИИ (рp. 4-6). 